\title{
A Practical Implementation of a Low-Cost 6-DOF IMU by Kalman Algorithm
}

\author{
Abdullah Ersan Oğuz ${ }^{1 *}$,Mustafa Emre Aydemir ${ }^{2}$ \\ 1* İstanbul Esenyurt Üniversitesi, Mühendislik Mimarlık Fakültesi, Elektrik Elektronik Mühendisliği Bölümü, İstanbul, Türkiye, (ORCID: 0000-0003-3413-7876), \\ abdullahersanoguz@esenyurt.edu.tr \\ 2 İstanbul Esenyurt Üniversitesi, Mühendislik Mimarlık Fakültesi, Elektrik Elektronik Mühendisliği Bölümü, İstanbul, Türkiye, (ORCID: 0000-0002-9285-5115), \\ mustafaaydemir@esenyurt.edu.tr \\ (International Conference on Design, Research and Development- 20 - 22 October 2021)
}

(International Conference on Design, Research and Development (RDCONF) 2021 - 15-18 December 2021)

(DOI: 10.31590/ejosat.1040765)

ATIF/REFERENCE: Abdullah Ersan OĞUZ, Mustafa Emre AYDEMİR (2021). A Practical Implementation of a Low-Cost 6-DOF IMU by Kalman Algorithm. European Journal of Science and Technology, (32), 167-170.

\begin{abstract}
In this study, the implementation of a 6 Degree of Freedom (DOF) Inertial Measurement Unit (IMU) via the Kalman Filter is aimed. High accuracy IMU units have been in practical use since the first space navigation practices. Today, the need for IMU's have been widespread among every aspect of life. The IMU sensors are mostly solid-state devices and are manufactured with Micro Electromechanical System (MEMS) technologies. The sensor noise has to be eliminated. The most popular method is the Kalman Filtering. The aim of this study is to better explain the IMU concept and make a practical implementation of the Kalman Filtering which is somehow complicated. In this study, a low cost IMU MEMS sensor has been selected and Kalman Filtering has been applied for both one and multi-dimensional outputs. The steps are explicitly explained to help the reader better understand the process. The study may be easily tailored to other sensor systems where noise is a concern.
\end{abstract}

Keywords: Sensors, Navigation, Noise, Kalman Filtering

\section{Kalman Algoritması ile Düşük Maliyetli 6-DOF IMU'nun Pratik Bir Uygulamasi}

Öz

Bu çalışmada, 6 Serbestlik Dereceli (DOF) Ataletsel Ölçüm Biriminin (IMU) Kalman Filtresi üzerinden uygulanması amaçlanmaktadır. Yüksek doğruluklu IMU birimleri, ilk uzay seyrüsefer uygulamalarından bu ana değin pratik kullanımda olmuştur. Günümüzde IMU'lara duyulan ihtiyaç hayatın her alanında yaygınlaşmıştır. IMU sensörleri çoğunlukla katı hal cihazlarıdır ve Mikro Elektromekanik Sistem (MEMS) teknolojileriyle üretilirler. Sensör gürültüsü ortadan kaldırılmalıdır. En popüler yöntem Kalman Filtresidir. Bu çalışmanın amacı, IMU kavramını daha iyi açıklamak ve nispeten karmaşık olan Kalman Filtrelemenin pratik bir uygulamasını yapmaktır. Bu çalışmada düşük maliyetli bir IMU MEMS sensörü seçilmiş ve hem tek hem de çok boyutlu çıktılar için Kalman Filtreleme uygulanmıştır. Adımlar, okuyucunun süreci daha iyi anlamasına yardımcı olmak için belirgin şekilde açıklanmıştır. Çalışma, gürültünün önemli olduğu diğer sensör sistemlerine kolaylıkla uyarlanabilir.

Anahtar Kelimeler: Sensörler, Navigasyon, Gürültü, Kalman Filtreleme

\footnotetext{
* Corresponding Author: abdullahersanoguz@esenyurt.edu.tr
} 


\section{Introduction}

In order to keep a platform steady, its current attitude has to be known. A device that measures the attitude of a platform is called the Inertial Measurement Unit (IMU). The IMU's measure and signal-condition the linear and gyroscopic accelerations in order to acquire the attitude information. Such stabilization platforms are widely used in military, civilian and industrial fields.

High-precision is obtained by using fiber-optical or lased based mechanical sensors. However, these types of systems are either very expensive or not miniaturized enough to fit in small volumes [1]. Recently, due to the advances in Micro Electromechanical System (MEMS) technologies, massproduced affordable solid-state sensors have been available widely. The disadvantage of these kids of sensors is that they are inherently noisy. The Kalman Filter is a very popular solution for noise removal. However, it is not very easy to implement and in most studies in the literature the details of the implementation are skipped, which makes it harder for the designer to apply the principles to a custom system.

In this study, it is aimed to implement the Kalman Filter on a widely available and affordable IMU sensor. The sensor which measures raw linear and gyroscopic acceleration values works as a slave to a microcontroller that implements the digital Kalman Filtering algorithm. The procedure is explained in detail. The algorithm is applied for one and multidimensional output data and the improved results are discussed at the conclusion.

The MPU-60X0 Series is a popular low-cost 6-axis motion tracking device that includes a 3 axis gyroscope and 3 axis accelerometer in an IC package [2] (Fig. 1).

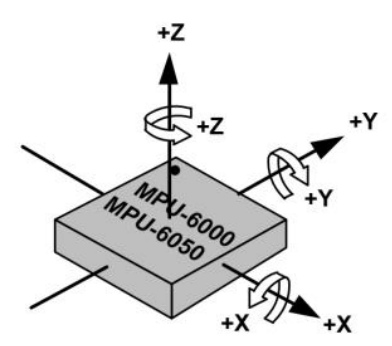

Figure 1. MPU60X0 Sensor Orientation of Axes of Motion and Polarity of Rotation

The sensor features a user-programmable gyroscope fullscale range of $\pm 250, \pm 500, \pm 1000$, and $\pm 2000 \%$ sec (dps) and a user-programmable accelerometer full-scale range of $\pm 2 \mathrm{~g}, \pm 4 \mathrm{~g}$, $\pm 8 \mathrm{~g}$, and $\pm 16 \mathrm{~g}$. In the current design $\pm 500 \mathrm{dps}$ and $\pm 8 \mathrm{~g}$ ranges are selected which are feasible values for navigation applications. The sensor has a digital output and communication with all registers of the device is implemented using inter-inter-circuit (I2C) protocol at $400 \mathrm{kHz}$. A microcontroller receives the data and signal processes it before forwarding to the navigation unit CPU.

The study may be expressed in 2 steps:

Step 1: The raw linear and gyroscopic sensor values are read from the sensor and are signal conditioned by the microcontroller thus yielding the attitude data.
Step 2: The attitude data is further conditioned by Kalman Filter to decrease noise.

The principal axes for an aircraft are defined as pitch, roll and yaw (Fig. 2). In this study, only the pitch and

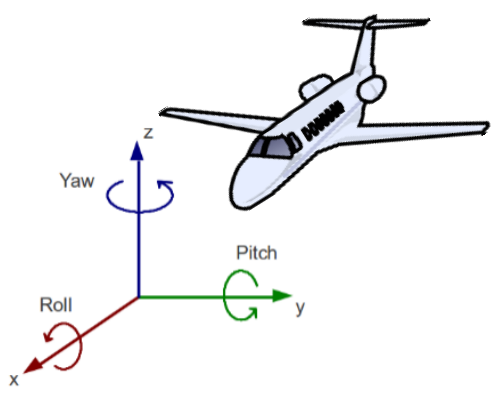

Figure 2. Principal axes for an aircraft

roll axes are going to be acquired for better understanding of the process without making things too complicated.

\section{Implementation}

With the start of the system, the registers are set up for the chosen acceleration ranges. The gyroscopic acceleration values are taken at $250 \mathrm{~Hz}$ and 1 degree corresponds 65,5 therefore the raw pitch $(\theta)$ and roll $(\phi)$ angles are accumulated as:

$$
\begin{aligned}
\theta_{\text {gyro-raw }} & =\frac{\text { gyro reading }}{250 * 65,5} \\
\phi_{\text {gyro-raw }} & =\frac{\text { gyro reading }}{250 * 65,5}
\end{aligned}
$$

in degrees. This process is valid only if there is no change in the yaw $(\psi)$ axis which is impossible for a 3 -dimensional system. As the aim is measuring the inclination angles $(\theta$ and $\phi)$, the yaw-axis compensation is implemented as:

$$
\begin{gathered}
\theta_{\text {gyro-corrected }}=\phi_{\text {raw }} * \sin (\psi) \\
\phi_{\text {gyro-corrected }}=-\theta_{\text {raw }} * \sin (\psi)
\end{gathered}
$$

The compensated gyro values are quite accurate. However, they suffer from accumulation error as the number of samples increases. Therefore, linear acceleration values are needed for better results.

$$
\begin{aligned}
& \theta_{\text {acceleration }}=\sin ^{-1}\left(\frac{a y}{\sqrt{a x^{2}+a y^{2}+a z^{2}}}\right) \\
& \phi_{\text {acceleration }}=\sin ^{-1}\left(\frac{a x}{\sqrt{a x^{2}+a y^{2}+a z^{2}}}\right)
\end{aligned}
$$

where $a x, a y$ and $a z$ are given as the acceleration data in the cartesian coordinate system, respectively. The problem with the linear acceleration values is that they are very prone to noise. Without filtering, it is impractical to use this data in any application A novel method was applied by combining the gyro and acceleration values in [3]. Here the final values are calculated by:

$$
\theta=\theta_{\text {gyro-corrected }} * 0,9996+\theta_{\text {acceleration }} * 0,0004
$$




$$
\phi=\phi_{\text {gyro-corrected }} * 0,9996+\phi_{\text {acceleration }} * 0,0004
$$

This is a very simple, yet efficient formulation for compensating the gyroscopic and linear acceleration measurement errors. However, it does not eliminate the noise. The next step is application of the Kalman Filter.

\section{Kalman Filter: 1-Dimensional (1-D) Case}

The Kalman Filter is selected because it efficiently estimates the state of a process, in a way that makes minimum the mean of the squared error (MSE). The filter supports estimates of past, present, future states of the output and filters the measurement and process noise. In the study, the method has been applied directly to the pitch and roll angles, independent from each other, which is a simple version of the Kalman Filter [4]. In the proceeding section the complementary Kalman Filtering method has been explained.

The 1-D case is relatively simple. The iterative flowchart is shown in Fig. 3.

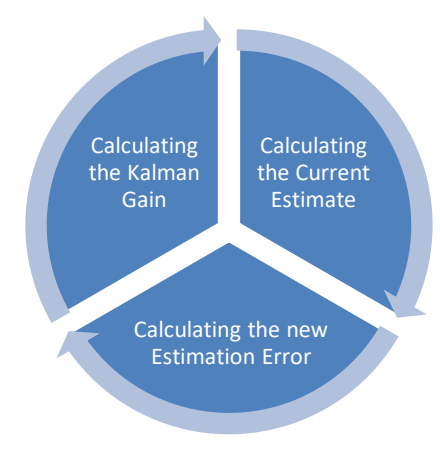

Figure 3. 1-D Kalman Filtering Process

The Kalman Gain $(K G)$ is calculated by:

$$
K G=\frac{E_{E S T}}{E_{E S T}+E_{M E A}}
$$

where, $E_{E S T}$ is the estimation error and $E_{M E A}$ is the measurement error. Next the current estimate is calculated as:

$$
E S T_{t}=E S T_{t-1}+K G\left[M E A-E S T_{t-1}\right]
$$

where $E S T_{t}$ and $E S T_{t-1}$ are the current and past estimates and $M E A$ is the measured value. Finally, the estimation error is updated as:

$$
E_{E S T_{t}}=[1-K G] E_{E S T_{t-1}}
$$

and the process continues iteratively. The 1-D filter has been applied at the pitch angle output of 8000 samples and the result is shown int Fig. 4. It can be clearly seen that the output has improved.

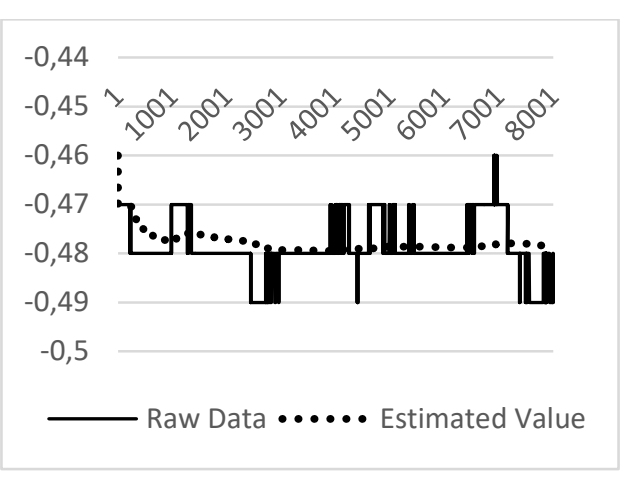

Figure 4. Pitch angle after 1-D Kalman Filter applied

\section{Kalman Filter: Multi Dimensional Case}

In order to make more accurate estimates, the number of input variables may be increased. This leads to more realistic modelling of the dynamic system. The Kalman filter may be regarded similar to the hidden Markov model, with the difference that the hidden state variables are continuous space as opposed to a discrete state space as for the hidden Markov model [5]. The details of the algorithm is well defined in the literature and only brief information will be given here.

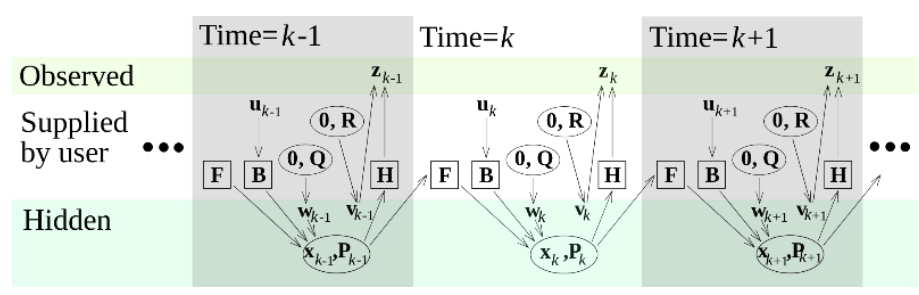

Figure 5. The Kalman Filter Algorithm [5]

In Fig. 5, the abbreviations may be listed as:

- $\boldsymbol{F}_{\boldsymbol{k}}$, the state-transition model;

- $\boldsymbol{H}_{\boldsymbol{k}}$, the observation model;

- $\mathbf{Q}_{\mathbf{k}}$, the covariance of the process noise;

- $\boldsymbol{R}_{\boldsymbol{k}}$, the covariance of the observation noise;

- and $\boldsymbol{B}_{k}$, the control-input model, for each time-step, $\mathrm{k}$

It is assumed that the true state at time $\mathrm{k}$ is derived from the state at $(\mathrm{k}-1)$ discrete-time interval according to:

$$
X_{k}=F_{k} X_{k-1}+B_{k} U_{k}+w_{k}
$$

where;

- $\boldsymbol{B}_{\boldsymbol{k}}$ is the control-input model and

- $\boldsymbol{w}_{\boldsymbol{k}}$ is the process noise.

during time interval $\mathrm{k}$, a measurement $\boldsymbol{z} \boldsymbol{k}$ of the true state $\boldsymbol{X} \boldsymbol{k}$ is implemented:

where;

$$
z_{k}=H_{k} X_{k}+v_{k}
$$


- $\boldsymbol{H}_{\boldsymbol{k}}$ is the observation model and

- $\boldsymbol{v}_{\boldsymbol{k}}$ is the observation noise.

Most real-time systems produce many sequential measurements in order to obtain the state of a system, rather than taking a single measurement. These many measurements are then combined to produce the state of the system at the desired time instant.

For example, consider the problem of pinpointing the attitude of an IMU inside a vechile. The IMU can be fitted with a Global Positioning System unit that can provide position estimation within a few metres. GPS forecasts are noisy; the readings can jump around quickly, although they are always within a few meters of the actual position. The position of the vechile can also be predicted by monitoring the acceleration and rate gyro, integrating speed and direction with respect to time.

The Kalman filter has been operating in two separate phases: prediction and update. In the estimation phase, the old location of the vechile changes according to Newton's laws of motion. Not only will a position estimate be calculated, but a new covariance is also calculated. Next, in the update phase, a measurement of the vechile's position is acquired from the Global Positioning System. With this measurement some uncertainty is introduced, and the ratio of its coincidence to the covariance of the estimate from the previous phase determines the amount of effect of the new measurement to the updated estimate. Ideally, as the longline estimates move away from the true position, the GPS measurements pull the position estimates towards the true position in a way that is neither fast-paced nor noisy.

\section{Conclusion}

In this study, the measurements of a low-cost IMU have been signal-conditioned to remove the effects of instantaneous and accumulative errors. The output has been further improved by eliminating measurement noise with 1-dimensional Kalman Filter. In the next section multi-dimensional Kalman Filter is explained briefly and it has been shown that the same procedure may be applied for sensor fusion using matrices (12-13).

The method may be applied for many similar applications for getting better results where noise and measurement errors are eliminated as much as possible.

\section{References}

[1] Yanbin Gao S. Li, Meng G., Wang G., Guan L., (2019), Accelerometer-Based Gyroscope Drift Compensation Approach in a Dual-Axial Stabilization Platform, MDPI Electronics Journal, 8, 1-12, https://doi.org/10.3390/electronics8050594

[2] MPU-6000/MPU-6050 Product Specification (2021, Aug 27), https://invensense.tdk.com/wp-content/uploads/2015 102/MPU-6000-Datasheet1.pdf

[3] Ariffin N. H., Bais B., Arsad N., (2016, November 14-16), Low Cost MEMS Gyroscope and Accelerometer Implementation without Kalman Filter For Angle Estimation, Proceedings of the International Conference on Advances in Electrical, Electronic and System Engineering, Malaysia, 7782, https://doi.org/10.1109/ICAEES.2016.7888013

[4] Okatan A., Aydemir M.E., (2007 June 14-16), Design and Implementation of a Precision Accelerometer by Recursive
Filtering for Spacecraft Instrumentation, Proceedings of the 3rd International Conference on Recent Advances in Space Technologies, Turkey, 444-447, https://doi.org/10.1109/RAST.2007.4284030

[5] Oğuz A. E., Temeltaş H., (2013). On the Consistency Analyzing of A-SLAM for UAV Navigating in GNSS Denied Environment. Acta Polytechnica Hungarica, 10(4), 119-132., https://doi.org/10.12700/APH.10.04.2013.4.7. 